\title{
Reduction of interferometric crosstalk induced penalty using a saturated semiconductor optical amplifier
}

Liu, Fenghai; Zheng, Xueyan; Poulsen, Henrik Nørskov; Wolfson, David; Jeppesen, Palle

Published in:

Lasers and Electro-Optics Society

Link to article, DOI:

10.1109/LEOS.2000.890783

Publication date:

2000

Document Version

Publisher's PDF, also known as Version of record

Link back to DTU Orbit

Citation $(A P A)$ :

Liu, F., Zheng, X., Poulsen, H. N., Wolfson, D., \& Jeppesen, P. (2000). Reduction of interferometric crosstalk induced penalty using a saturated semiconductor optical amplifier. In Lasers and Electro-Optics Society (Vol. 1). IEEE. https://doi.org/10.1109/LEOS.2000.890783

\section{General rights}

Copyright and moral rights for the publications made accessible in the public portal are retained by the authors and/or other copyright owners and it is a condition of accessing publications that users recognise and abide by the legal requirements associated with these rights.

- Users may download and print one copy of any publication from the public portal for the purpose of private study or research.

- You may not further distribute the material or use it for any profit-making activity or commercial gain

- You may freely distribute the URL identifying the publication in the public portal 


\title{
Reduction of interferometric crosstalk induced penalty using a saturated semiconductor optical amplifier
}

\author{
Fenghai Liu, Xueyan Zheng, Henrik N. Poulsen, David Wolfson, Palle Jeppesen \\ Research Center COM, Technical University of Denmark, Building 349, Lyngby, DK-2800, Denmark \\ Telephone: +45-45253845, Fax: +45-45936581, Email: lf@com.dtu.dk
}

\section{Introduction}

WDM networks have been installed on a global scale to satisfy the ever-increasing demand of communication capacity. As the number of wavelength increases, the interferometric crosstalk is becoming critical. Strong requirements on crosstalk are imposed to the components used in largescale transparent optical networks.[1,2]

Components with low crosstalk are important, but other effective techniques to suppress the impact of crosstalk are also needed. Several techniques can be used for this purpose, e.g., using a gain saturated laser diode amplifier [3], wavelength conversion based on cross-phase-modulation [4] or cross-gain-modulation [5,6] in semiconductor optical amplifiers (SOA).

The gain saturated laser diode amplifier needs a filter to suppress the lasing signal from the diode and it is limited to low bit-rate. To suppress the crosstalk, wavelength conversion is not always necessary. For instance, a tunable source is needed to track the wavelength of input signal in the wavelength converter in order to keep the same wavelength for the input and output signals, which is complex and expensive. SOA has a fast gain saturation, which can be used to suppress the fluctuation on the optical amplitude. A holding $\mathrm{CW}$ light counter-propagating with the input signal is used to overcome waveform distortion in the saturated SOA. This scheme avoids wavelength conversion. Since the SOA is of simple structure and bit-rate transparent at high speed, it is promising in reduction of crosstalk impact in transparent optical networks.

\section{Experiment and results}

Fig. 1 shows the experimental set-up to demonstrate the capability of reducing the crosstalk induced power penalty using a saturated SOA.

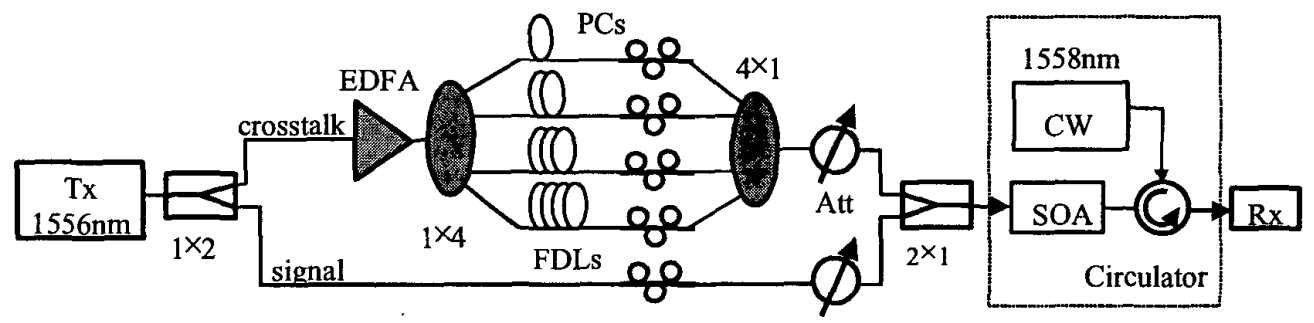

Fig.1. Experimental set-up. Tx: transmitter; $\perp \times 2$ and $2 \times 1$ : $3 \mathrm{~dB}$ coupler; $1 \times 4$ and $4 \times 1$ : star coupler; PC: polarisation controller; FDL: fibre delay line; Rx: PIN receiver.

The power from the transmitter is split into two parts; one part serves as signal, and the other part as crosstalk. The crosstalk part is amplified by an EDFA and further divided into four parts using a $1 \times 4$ star coupler in order to simulate four crosstalk terms. The four crosstalk terms are decorrelated by different lengths of fibre delay lines, aligned in the same polarisation state as the signal for maximum impact using polarisation controllers and combined again using a $4 \times 1$ star coupler. The crosstalk contributions are attenuated and combined with the signal. Another attenuator is used to control the power into the saturated SOA. Bit error rate (BER) curves are measured with and without the SOA before the PIN receiver. Optimal decision threshold is used in the BER measurement. 
In order to overcome the waveform distortion when the SOA is saturated, a holding light in $\mathrm{CW}$ operation at $1558 \mathrm{~nm}$ is injected into the SOA through a circulator, counter-propagating with the input signal, as shown in a dashed frame in Fig. 1.

The transfer characteristic of the saturated SOA is shown in Fig.2 when the power of $\mathrm{CW}$ light is $6.1 \mathrm{dBm}$. From the transfer characteristic, it can be found that the SOA is highly saturated when the input power is higher than $0 \mathrm{dBm}$. The average input power into the SOA is $1 \mathrm{dBm}$ in our experiment in order to suppress the crosstalksignal beat noise on the " 1 " level.

Since SOA is bit-rate transparent, the saturated SOA is used to reduce the crosstalk impact at both $2.5 \mathrm{~Gb} / \mathrm{s}$ and $10 \mathrm{~Gb} / \mathrm{s}$. Fig.3 shows the eye-diagrams with $-15 \mathrm{~dB}$ crosstalk before (a) and after (b) the SOA at

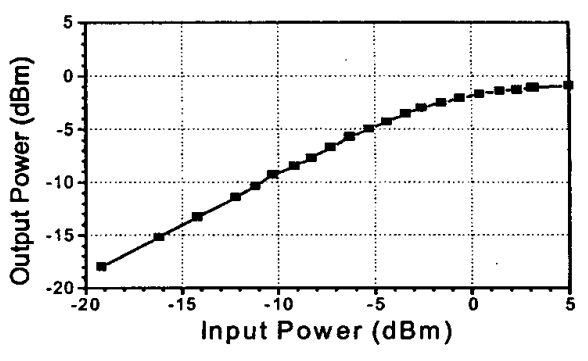

Fig.2. Transfer characteristic of the SOA saturated by a CW light of $6.1 \mathrm{dBm}$ $2.5 \mathrm{~Gb} / \mathrm{s}$. A clearer eye can be seen after using the SOA. Fig. 4 shows the penalty curves versus relative crosstalk power at $10 \mathrm{~Gb} / \mathrm{s}$. A $4 \mathrm{~dB}$ more crosstalk power can be tolerated at $1 \mathrm{~dB}$ penalty when the saturated SOA is used.

Using saturated SOA will significantly relax the crosstalk requirement on the components used in cascade in transparent optical networks where interferometric crosstalk accumulates.

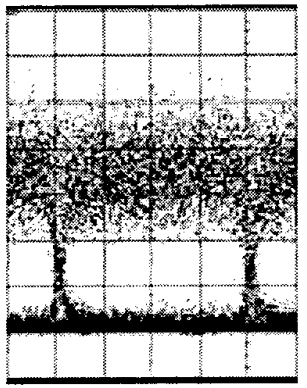

(a)

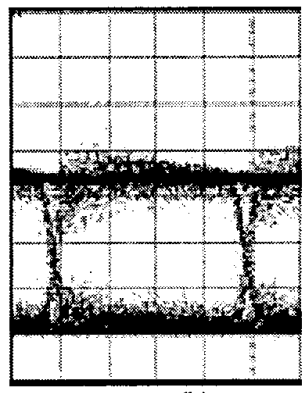

(b)

Fig.3. Eye-diagrams before (a) and after SOA. Time scale: $100 \mathrm{ps} / \mathrm{div}$

\section{Conclusion}

We successfully demonstrated that a simple saturated SOA could be used to reduce the impact from the interferometric crosstalk at $2.5 \mathrm{~Gb} / \mathrm{s}$ and $10 \mathrm{~Gb} / \mathrm{s}$. It is shown that $4 \mathrm{~dB}$ more crosstalk power can be tolerated at $1 \mathrm{~dB}$ penalty by using the SOA. This will greatly reduce the crosstalk requirement on components, especially these used in cascade in large-scale transparent optical networks.

\section{Reference:}

[1] Ho K.P., et al., IEEE J. Lightwave Techn. 14, 1127-1135(1996)

[2] Liu F., et al., Technical Digest. of CLEO98, 318-319(1998)

[3] Inoue K., IEEE Photonics Techn. Lett., 8(3), 458-460(1996)

[4] Poulsen H.N., et al., Proc. of OAA 98, 181-183(1998)

[5] Pegg S.I., et al., IEEE Photonics Techn. Lett., 11(6), 724-726(1999)

[6] Stephens M.F.C., et al., IEEE Photonics Techn. Lett., 11(8), 979-981(1999) 